\title{
Learning Through Games: An Approach for Children with Autism Spectrum Disorder During COVID-19 Pandemic
}

\author{
Nurul Hidayah Mat Zain ${ }^{1}$, Farah Athirahmohd Farif $^{2}$, Norshahidatulhasana Ishak ${ }^{3}$, Siti \\ Nuramalina Johari ${ }^{4}$, Anita Mohd Yasin ${ }^{5}$, Nor Azida Mohamed Noh ${ }^{6}$
}

1,2,3,4,5,6 Faculty of Computer and Mathematical Sciences, UiTM Cawangan Melaka, KampusJasin, 77300 Merlimau, Melaka

Article History: Received: 11 January 2021; Accepted: 27 February 2021; Published online: 5 April 2021

\begin{abstract}
The coronavirus disease (COVID-19) pandemic has led to increased online learning for students, including children with Autism Spectrum Disorder (ASD). However, the need for social distancing has interrupted the delivery of continuing education for ASD children. ASD emerges in early childhood, which may cause interruptions in numerous essential areas of progress in daily life. Therefore, we proposed a mobile game, namely Basic Daily Life (BasLife) game, for ASD children. The game offered positive affection and an enjoyable experience in learning sessions during the COVID-19 pandemic. The Rapid Application Development (RAD) methodology was implemented to produce the BasLife game. The RAD methodology consists of four phases: Requirement Planning Phase, User Design Phase, Development Phase, and Cutover Phase. The EGame Flow Model was applied as a guideline to develop an enjoyable game during the User Design Phase and Development Phase. Keenly, the study results produce theBasLifegame as a learning approach for ASD children that would tackle the interpersonal skills and create an enjoyable learning experience during the COVID-19 pandemic.
\end{abstract}

Keywords: COVID-19, Autism Spectrum Disorder, EGame Flow Model, online learning, computer games.

\section{Introduction}

Children diagnosed with Autism Spectrum Disorder (ASD) are detected through symptoms such as insufficiency in repetitive patterns of activities[1]. Thus, repetitive and regular updating of specific knowledge and skills for children with ASD is essential. However, the need for social distancing due to the COVID-19 pandemic cause disrupted the continuing learning process[2]. During the pandemic, the ASD children had to swiftly move to virtual learning or self-learning settings guided by parents and instructors. In this challenging situation, mobile learning may offer significant advantages because it requires no physical demonstration. Learners can learn from prepared learning materials or live simulations. This approach more interactive with the combination of game elements in the learning materials. The mobile game should be used as a new aim in gaming technologies for education. It can also be therapeutic at the same time [3].

Moreover, learning should be conducted in an enjoyable way for game activity in which a challenging goal is to pursue arranged rules [4]. Simultaneously, to polish the ASD children with knowledge, skills, and nurture the interest in learning during a COVID-19 pandemic. The game will meet the fundamental needs of learning, which provide amusement, inspiration, enthusiasm, obsessive involvement, and excitement [5].

The capability to focus attention on task-relevant material is crucial for learning[6].Since most children with ASD is hard to get their attention in learning to handle things, game-based learning integrates learning and enjoyment into one mobile game[7]-[9]. The purpose of implementing the enjoyment experience is that the player may play together with the game's character, suitable for the ASD children[10]. Linking game platform and ASD children offered goals to achieve or the highest score in the game. Besides, ASD children can practice slowly improve their daily life generalization by developing this game. This project aims to conduct a game that consists of enjoyable elements at the same time to polish the ASD children with basic daily life skills and nurture the interest in learning skills of basic daily life.

\section{Background Study}

\section{Children with ASD}

ASD is categorized by insufficiencies in social communication and common contact throughout several circumstances and obstructive and tedious behaviour repetitions, interests, or activities[10], [11]. Most ASD children face poor eye contact, have difficulty in routine changes, picky eaters, and have a tantrum [4]. Hence, it is crucial to provide a specific learning environment for these children, especially during the COVID-19 pandemic. Designing technologies for ASD children has become a learning outcome and technology-based education intervention. It will develop an advantage when professionally designed programs help ASD children attain skills in increasing adaptive functioning[12]. These mobile games will support the learning in the core 
areas of difficulty characteristics such as social communications and interactions [5]. Using technologies such as a mobile game for ASD children in daily life will appear useful and appreciated by the children, but it depends on how they use much training.

Besides, the ASD children who are playing the game will be encouraged to combine knowledge from different areas to choose a solution or to decide at one point [13]. This kind of learning process relates to achievement, imitating, understanding, and applying. The game should be motivated so that the ASD children will repeat the sequence within the game context. Being motivated is the feature of practical learning that needs to be maintained through feedback responses and participation to take place for intended learning.

\section{Basic Daily Life Activities}

Children have been continuously born with a potency that is eager to discover their environments. It is an important activity to make sure that they get to set objects in order. Children must make it their custom activities; therefore, they would not lose any skills as time goes on. Abilities improve increasingly, and a child may need much support and encouragement to be significant in a chore.

ASD children struggle with essential daily physical activity in the social and built environment. To overcome these barriers, ASD children need the extra focus of activities to help them face these difficulties[14]. Children's activity performance should be developing their abilities to become a social being. Learning and mastering certain activities that are related can improve skills. In daily life activities, children should explore, participate, and imitate certain behaviours[15].

\section{Activities in Basic Daily Life for ASD Children}

ASD children must develop their activities stage by stage. The first stage of activity is sensory play, which means revolving around during activities. Sensory play can be intellectualized as a fun activity in which children were contributed. Children should treat play skills using many inspection tools [16]. The second stage is exploratory and manipulative play, as the children gradually learn about the world around them. Activities are part of children's daily lives; thus, it is compulsory to give them opportunities to develop essential skills [17]. The third stage is illusory play, which means they will start to explore things for their physical features. It is essential to involve family, especially parents or guardians, to include together in illusory play because children without playmates will not be majoring in companionship and emotional support [18].

ASD children at the age of 4 to 6 years old are still in the learning stage and wanted to know their surroundings, especially when they spend the most at home, such as during the COVID-19 pandemic. Involving activities of daily life should be a therapy practice [19]. Activities of daily living such as eating, toileting, and dressing are priorities for parents with ASD children. It tends to develop their children in becoming independent and decreasing the amount of assistance at home.

\section{Methodology}

Developing an enjoyable game design for ASD children is a critical phase. The BasLife game was developed using RAD methodology to ensure the users' needs with a short amount of time, high quality, and lowest cost. The RAD methodology consists of four phases: Requirement Planning Phase, User Design Phase, Development Phase, and Cutover Phase. Several iterations of development may occur within a user design phase and development phase to refine the game based on user testing and feedback.

\section{Requirement Planning Phase}

In Requirement Planning Phase, all information gathered will support the initial and context product. Numerous methods are expended, such as contextual inquiry, interviews, surveys, brainstorming, online journals, articles, user profiles, and strategy development. These methods are used to find the information and solution for the project's objectives, problem statement, scope, and literature review. The concept of adventure-puzzle learning games has been studied through the sources. To complete the game, hardware, software, and data requirements for the gamemust be analyzed.

\section{User Design Phase}

The User Design Phase contains the designing process, such as character design, environment design, props, and asset design, as shown in Figure 1 (a) and (b). Besides, the flowchart is used to define each work's steps in the development of the game. Meanwhile, the storyboard prepared to visually define game design, creating it at ease in evolving the game while relating the interface design. 


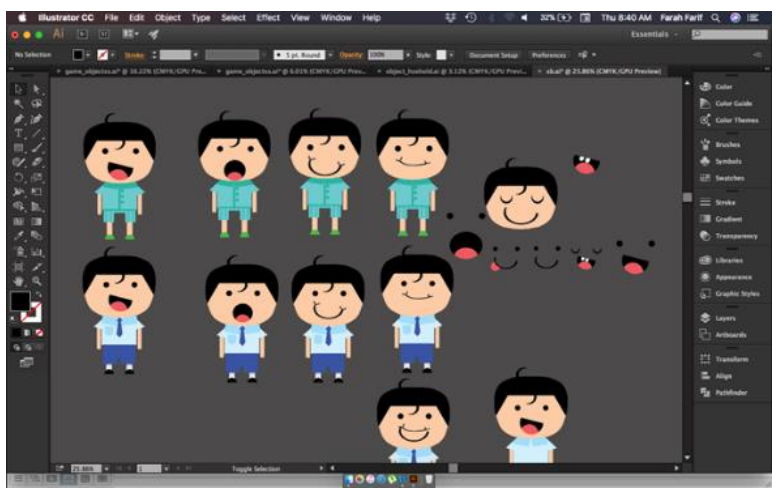

(a)

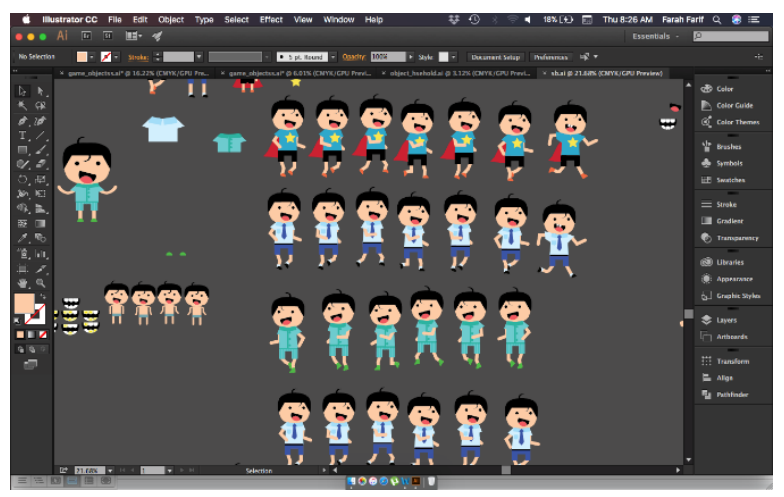

(b)

Figure1 (a) and (b): Part of the character design process

Development Phase

The Development Phase is the phase that transforms which part has been designed in command to produce a specific creation. In this current phase, all the thorough interface, design, and code was developed. The project development phase involves assimilating various diverse platforms and authoring tools. Every function is linked with the event sheets in authoring tools, which already together with the game engine. Most of the game layouts are designed consequently as a storyboard, and some vaguely changed in the scene. Every object material used in this game is designed using Adobe Illustrator software, roughly based on the storyboard.

The EGameFlowModel [20]criteria are applied in the BasLifegame to enhance the players' enjoyment experienced while playing the game. An EGameFlow enjoyment model is essential to be employed in this game development. However, the criterion applied in this game does not include the social interactionelementbecause this game's playability is offline and does not support social interaction between players, such as chatbox. Table 1 shows part of the screenshots of Baslifewith game elements based on the EGame Flow Model aligned with the learning objectives. We expected children to play the BasLife in their home setting during the COVID-19 pandemic.

Table1: Development of BasLifegame that implemented elements EGame Flow Model

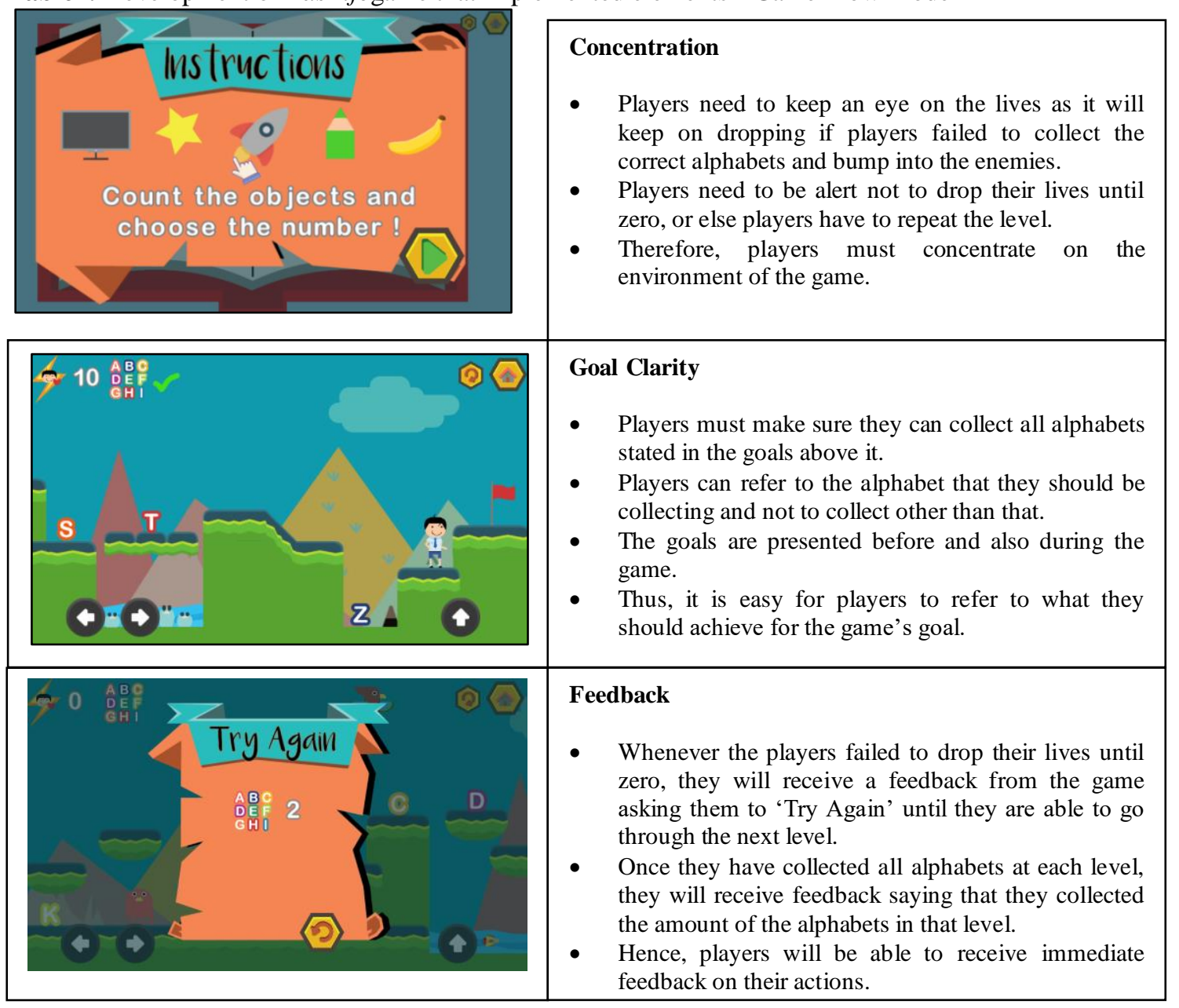



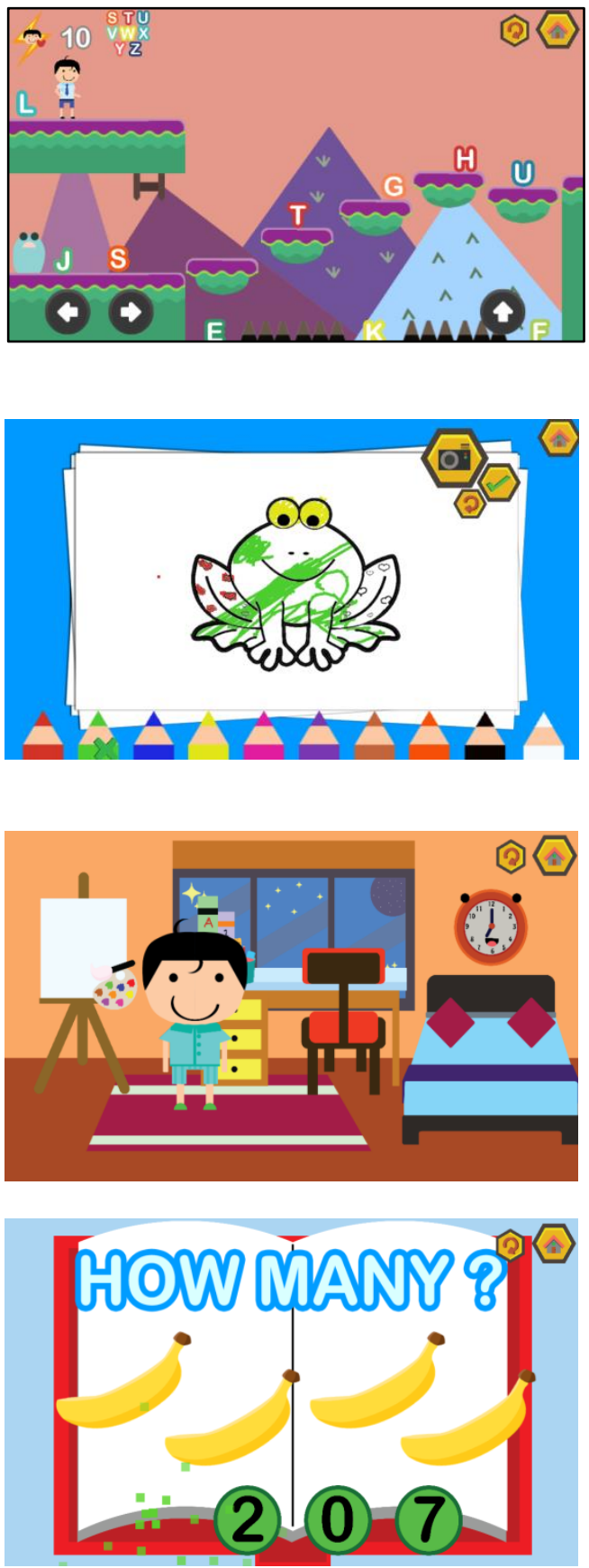

\section{Challenge}

- Players are given the instruction and hints on what they should do in the game with the illustration of objects to make it much more interesting and attractive since it is for the targeted user.

\section{Autonomy}

- In the drawing game, players will be able to feel free to express their thoughts and fill in the colors.

- At this game, they will be able to have much more control over the game.

\section{Immersion}

- The situation and surroundings of each layout portray the environment of our real life, hence children will feel more immerse in the game as what they see in their everyday life in the real world.

- The implementation of the colors makes it more interesting for players to learn and sharpen their daily life skills

\section{Knowledge Improvement}

- The mathematics game of counting objects will enable players to learn from their mistake, which means that if they choose the wrong answer they would still be able to continue playing the mathematics game.

- With this way, players will be able to improve their knowledge when they tend to repeat the same things over and over again.

- Therefore, plavers are motivated to integrate the

\section{Cutover Phase}

The cutover Phaseis a phase to evaluate the game. At this evaluation phase, the user is given a set of questionnaires once they have played the game. In this project, target users are ASDchildren between the ages of 6 and 12 years old and at the mild stage of the disorder. It is compulsory to get feedback from the scope once they have to use the product. It is essential to achieve the game's objective, which is to adapt an enjoyment to these children.

The enjoyment of the game evaluated over enjoyment evaluation using the EGameFlow model. There are eight criteria for enjoyment:Concentration, Goal Clarity, Feedback, Challenge, Control, Immersion, Social Interaction, and Knowledge Improvement (Daniel, Revisiting, Sweetser, \& Wyeth, 2012). The social interaction element is excluded because the game's playability is offline and does not support social interaction between players, such as the chatbox. 


\section{A. Participants}

The target participants that were involved were kindergarten children with ASD. The age of each target user involved in this evaluation was five years old. The evaluation was conductedby spreading the questionnaire with feedback from participants was guided by teachers. Starting a conversation to get an evaluation is a way to complete the questionnaire. The children involved in this evaluation have characteristics implying the ASD children such as hard to communicate, isolate self when alone but mingle around when they are with friends. In order to complete the measurement of the evaluation, the process has been done individually. The target area to gather the participants is in Jasin, Melaka. The total participants that were involved are eight respondents.

\section{B. Procedure and Instrument}

The researcherbriefsthe teachers and participants about how to play the BasLifegame. It took about approximately 8 to 10 minutes to complete the game. After the participants completed play the game, they were asked to answer the questionnaire regarding their enjoyable experience while playing the game. The teacher guides the children to complete the evaluation.AnEGameFlow Model [20]instrumentwas refer to evaluatesanASD children's enjoymentafter play the Baslife game, which contains eight aspect elements of enjoyment, such as Concentration, Goal Clarity, Feedback, Challenge, Control, Immersion, Social Interaction, and Knowledge Improvement. The questionnaire stated in the English Language,andemoticon guidance(Figure 2) shows which feelings are their current reaction.

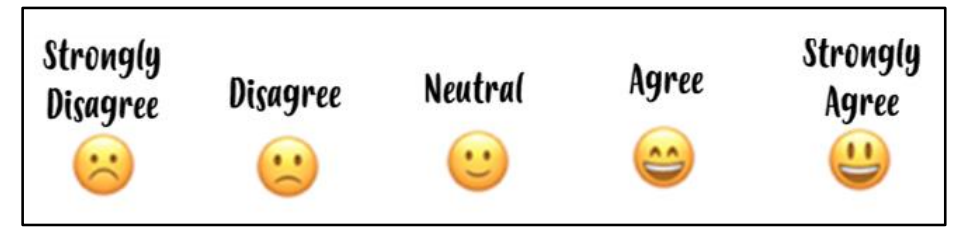

Figure 2: Emoticon guidance in instruments

\section{Result and Findings on Evaluation of BasLifeGame}

\section{Demography Participants}

Table 2 showeddemography eight respondents ASD children were involved in this evaluation, including four $(50 \%)$ females and four $(50 \%)$ males. There are $7(87.5 \%)$ ASD children preferable to play educational games instead of books, and only $1(12.5 \%)$ not preferable to play educational games.

The evaluation takes several sessions to complete. For each session, children played the BasLife game for 10 minutes. During the gameplay sessions, the teacher was sitting or standingaside from the children, taking notes, and intervening when needed. All sessions took place in the sameroom without modification of the environment settings.

Table 2: Demography item

\begin{tabular}{|l|l|l|l|}
\hline Questions & Range & Frequency(s) & Percentage(\%) \\
\hline \multirow{2}{*}{ Gender } & Male & 4 & 50.0 \\
\cline { 2 - 4 } & Female & 4 & 50.0 \\
\hline \multirow{2}{*}{$\begin{array}{l}\text { Preferable to play educational games } \\
\text { instead of books }\end{array}$} & Yes & 7 & 87.5 \\
\cline { 2 - 4 } & No & 1 & 12.5 \\
\hline
\end{tabular}

\section{Concentration Element}

Table 3 shows the results frequencyof responses for Concentrationelement. These results show that the respondent response to all items with an agreeability scale. The result indicated that $5(62.5 \%)$ respondents more towards agreeing and strongly agree that most of the gaming activities are related to the learning task from the data gathered. The result also revealed that $7(87.5 \%)$ respondents agree that they can remain concentrated on the game. Besides, the results revealed that $7(87.5 \%)$ respondents more towards agreeing and strongly agree that they were not burdened with a task that seems unrelated. Only $1(12.5 \%)$ responded naturally to this statement. A total of $6(12.5 \%)$ respondents more towards agreeing and strongly agree that the workload in the game is adequate.

Table 3: Frequencyof responses for Concentrationelement

\begin{tabular}{|l|l|l|l|l|l|l|}
\hline Item & SD & D & N & A & SA & Mean \\
\hline Most of the gaming activities are related to the learning task & 0 & 1 & 2 & 3 & 2 & 3.75 \\
\hline No distraction from the task is highlighted & 0 & 0 & 2 & 3 & 3 & 4.13 \\
\hline
\end{tabular}




\begin{tabular}{|l|l|l|l|l|l|l|}
\hline Generally speaking, I can remain concentrated on the game & 0 & 0 & 1 & 5 & 2 & 4.13 \\
\hline $\begin{array}{l}\text { I am not distracted from tasks that the player should concentrate } \\
\text { on }\end{array}$ & 0 & 0 & 2 & 5 & 1 & 3.88 \\
\hline I am not burdened with task that seem unrelated & 0 & 0 & 1 & 3 & 4 & 4.38 \\
\hline Workload in the game is adequate & 0 & 0 & 2 & 3 & 3 & 4.13 \\
\hline & & & & & & $\mathbf{4 . 0 6}$ \\
\hline
\end{tabular}

SD: Strongly Disagree, D: Disagree, N: Neutral, A: Agree, SA: Strongly Agree,

\section{Goal Clarity Element}

Table 4 shows the result of the Goal Clarity element. The results show that $5(62.5 \%)$ respondents not sure to respond agree or disagree about game goals were presented at the beginning of the game. There were $4(50 . \%)$ respondentsmore towards agreeing that game goal was presented clearly. Moreover, 7 (87.5\%)respondents agreed that intermediate goals were presented at the beginning of each scene. The respondents asked whether the intermediate goals were presented clearly. The data recorded more than half of ASD children response positively agreed, and only $1(12.5 \%)$ response to disagree.

Table 4: Frequencyof responses for Goal Clarityelement

\begin{tabular}{|l|l|l|l|l|l|l|}
\hline Item & SD & D & N & A & SA & Mean \\
\hline Overall game goals were presented in the beginning of the game & 0 & 1 & 5 & 1 & 1 & 3.25 \\
\hline Overall game goals were presented clearly & 0 & 0 & 4 & 3 & 1 & 3.63 \\
\hline Intermediate goals were presented in the beginning of each scene & 0 & 0 & 1 & 5 & 2 & 4.13 \\
\hline Intermediate goals were presented clearly & 0 & 1 & 2 & 3 & 2 & 3.75 \\
\hline & & & & & & $\mathbf{3 . 6 9}$ \\
\hline
\end{tabular}

SD: Strongly Disagree, D: Disagree, N: Neutral, A: Agree, SA: Strongly Agree,

\section{Feedback Element}

Table 5 shows the results frequencyof responses for Feedbackelement. These results show that the respondents' response to all items with an agreeability scale. The result indicated that $7(87.5 \%)$ respondents agree and strongly agree that they receive feedback on the game's progress from the data gathered.The result also revealed that all respondents agree that they have been notified of new tasksand new events immediately. Moreover, the results revealed all the respondents more towards agreeing and strongly agree thatthey immediately receive information on the success (or failure) of intermediate goals.

Table 5: Frequency of responses for Feedbackelement

\begin{tabular}{|l|l|l|l|l|l|l|}
\hline Item & SD & D & N & A & SA & Mean \\
\hline I receive feedback on my progress in the game & 0 & 0 & 1 & 2 & 5 & 4.50 \\
\hline I receive immediate feedback on my actions & 0 & 0 & 2 & 2 & 4 & 4.25 \\
\hline I am notified of new task immediately & 0 & 0 & 0 & 3 & 5 & 4.63 \\
\hline I am notified of new events immediately & 0 & 0 & 0 & 3 & 5 & 4.63 \\
\hline $\begin{array}{l}\text { I receive information on my success (or failure) of intermediate } \\
\text { goals immediately. }\end{array}$ & 0 & 0 & 0 & 4 & 4 & 4.50 \\
\hline & & & & & & $\mathbf{4 . 5 0}$ \\
\hline
\end{tabular}

SD: Strongly Disagree, D: Disagree, N: Neutral, A: Agree, SA: Strongly Agree,

\section{Challenge Element}

Table 6 shows the results of the frequency of response for the Challenge element. This result shows the respondents' response to all items with an agreeability scale. The result indicated that $5(62.5 \%)$ respondents more towards agreeing and strongly agree that the game provides hints in the text that help them overcome the challenge. Meanwhile, all respondents disagree that the game provides online support that helps them overcome the challenge. This result was predicted because the game was offline, which is not connected with online support.

Moreover, all respondents agreed that the game provides video or audio auxiliaries that help them overcome the challenges. The result also revealed that $6(75 \%)$ respondents agreed and strongly agreed that the game provides different challenges tailored to different players. 
Table 6: Frequency of responses for Challengeelement

\begin{tabular}{|l|l|l|l|l|l|l|}
\hline Item & SD & D & N & A & SA & Mean \\
\hline $\begin{array}{l}\text { The game provides hints in text that help me overcome the } \\
\text { challenge }\end{array}$ & 0 & 2 & 1 & 5 & 0 & 3.38 \\
\hline $\begin{array}{l}\text { The game provides online support that help me overcome the } \\
\text { challenge }\end{array}$ & 6 & 2 & 0 & 0 & 0 & 1.25 \\
\hline $\begin{array}{l}\text { The game provides video or audio auxiliaries that help me } \\
\text { overcome the challenges }\end{array}$ & 0 & 0 & 0 & 3 & 5 & 4.63 \\
\hline The difficulty of the challenges increases as my skills improved & 0 & 0 & 0 & 2 & 6 & 4.75 \\
\hline The game provides new challenges with an appropriate pacing & 0 & 0 & 2 & 2 & 4 & 4.25 \\
\hline $\begin{array}{l}\text { The game provides different levels of challenges that tailor to } \\
\text { different players }\end{array}$ & 0 & 0 & 6 & 2 & 0 & 3.25 \\
\hline & & & & & & $\mathbf{3 . 5 8}$ \\
\hline
\end{tabular}

SD: Strongly Disagree, D: Disagree, N: Neutral, A: Agree, SA: Strongly Agree,

\section{Autonomy Element}

Table 7 shows the result of the frequency of responses forthe Autonomy element. These results show that 7 $(87.5 \%)$ respondents more towards agreeing and strongly agree that they feel a sense of control, impact over the game, and they know the next step in the game, respectively. The result revealed $4(50 \%)$ respondents more agree about feel a sense of control over the game. This scenario may happen because the game project provides the game's step-by-step process to guide the players.

Table 7: Frequencyof responses forAutonomy Element

\begin{tabular}{|l|l|l|l|l|l|l|}
\hline Item & SD & D & N & A & SA & Mean \\
\hline I feel a sense of control and impact over the game & 0 & 0 & 1 & 5 & 2 & 4.13 \\
\hline I know next step in the game & 0 & 0 & 1 & 4 & 3 & 4.25 \\
\hline I feel a sense of control over the game & 0 & 1 & 3 & 3 & 1 & 3.50 \\
\hline & & & & & & $\mathbf{3 . 9 6}$ \\
\hline
\end{tabular}

SD: Strongly Disagree, D: Disagree, N: Neutral, A: Agree, SA: Strongly Agree,

\section{Immersion Element}

Table 8 shows the result of the frequency of response for the Immersion element. The results show that all respondents agree and strongly agree that they forget about time passing while playing the game. All of them also agreed that they are unaware of their surrounding while playing the game. The result indicated that all respondents forget worries about everyday life while playing the game and experience an altered sense of time from the data gathered.The respondents asked whether they become and emotionally involved in the game. The data recorded $6(75 \%)$ respondents strongly agree with this statement, and only $2(25 \%)$ respondents agree with this statement.

Table 8: Frequencyof responses for Immersionelement

\begin{tabular}{|l|l|l|l|l|l|l|}
\hline Item & SD & D & N & A & SA & Mean \\
\hline I forget about time passing while playing the game & 0 & 0 & 0 & 1 & 7 & 4.88 \\
\hline I because unaware of my surroundings while playing the game & 0 & 0 & 0 & 1 & 7 & 4.88 \\
\hline $\begin{array}{l}\text { I temporarily forget worries about everyday life while playing the } \\
\text { game }\end{array}$ & 0 & 0 & 1 & 4 & 3 & 4.25 \\
\hline I experience an altered sense of time & 0 & 0 & 1 & 4 & 3 & 4.25 \\
\hline I can become involved in the game & 0 & 0 & 2 & 5 & 1 & 3.88 \\
\hline I can emotionally involve in the game & 0 & 0 & 0 & 2 & 6 & \\
\hline I feel viscerally involved in the game & 0 & 0 & 3 & 5 & 0 & 3.63 \\
\hline & & & & & & $\mathbf{3 . 6 8}$ \\
\hline
\end{tabular}

SD: Strongly Disagree, D: Disagree, N: Neutral, A: Agree, SA: Strongly Agree,

\section{Knowledge Improvement Element}

Table 9 shows the results of the frequency of response for the Knowledge Improvement element. The result indicated that $7(87.5 \%)$ respondents agree and strongly agree that they can catch the basic ideas of knowledge 
taught. All respondents agreed that the game motivates them to integrate the knowledge taught. The findings also revealed that all respondents agreed they want to know more about the knowledge taught.

Table 9: Frequencyof responses for Knowledge Improvement Element

\begin{tabular}{|l|l|l|l|l|l|l|}
\hline Item & SD & D & N & A & SA & Mean \\
\hline The game increases my knowledge & 0 & 0 & 1 & 5 & 2 & 4.13 \\
\hline I catch the basic ideas of the knowledge taught & 0 & 0 & 1 & 5 & 2 & 4.13 \\
\hline I try to apply the knowledge in the game & 0 & 0 & 0 & 6 & 2 & 4.25 \\
\hline The game motivates the player to integrate the knowledge taught & 0 & 0 & 0 & 3 & 5 & 4.63 \\
\hline I want to know more about the knowledge taught & 0 & 0 & 0 & 1 & 7 & 4.88 \\
\hline & & & & & & $\mathbf{4 . 4 0}$ \\
\hline
\end{tabular}

SD: Strongly Disagree, D: Disagree, N: Neutral, A: Agree, SA: Strongly Agree,

\section{Overall Mean}

Table 10 below shows the total overall mean for an enjoyable experience in playing the BasLife game. The total overall mean was computed from every total average mean for each element to identify the outcome of the evaluation based on theEGame Flow Model.

According to the table below, the highest average mean from all the elements stated is from Feedback elements with 4.50. It shows that this game provides feedback for each of the user's actions and progress. Thus, it makes it easiest for the user to complete the task given. It is parallel to research by [21] that Feedback is very important in game development especially for special needs as they know the process and progress of the game. Besides, implementing feedback engages and motivates the child to maintain focus and render assistance that must all be directly relevant to the learning task [22].

Next, the second-highest element is in Knowledge Improvement with 4.40. This result indicates that using BasLife game help ASD children to improve their knowledge in learning. These results are also supported by [23], which this paper agrees that games can maximize learning for Autism, indirectly improving their knowledge. Besides, the third-highest element is Concentration with 4.06. This result clearly shows that BasLife is not only a game, but it can be used as a platform for the user, especially children with ASD, to concentrate on learning progress.

Moreover, combining learning with the game might increase concentration [24]. However, flow theory suggests that learning engagement, such as concentration, is highest when perceived challenges and skills are wellmatched [23]. According to Table 10, the Challenge element got the lowest mean, related to the concentration. It can also be related to lack of focusing while reading the instructions given before playing the game.

The total overall mean result is 3.98, which shows that the enjoyable level has been stated. This result indicates that $79.6 \%$ of enjoyment experienced by ASD children in the BasLife game. The game elements of enjoyment are suitable to help ASD users improve knowledge and concentrate on learning while enjoying playing the game. The EGame Flow model is suitable to be implemented in the development of the game for Autism. Thus, BasLife is suitable as a game-based learning platformfor children with ASD during the COVID-19 pandemic.

Table 10: Overall mean for an enjoyable experience in BasLife

\begin{tabular}{|l|l|}
\hline Element & Mean \\
\hline Concentration & 4.06 \\
\hline Goal Clarity & 3.69 \\
\hline Feedback & 4.50 \\
\hline Challenge & 3.58 \\
\hline Autonomy & 3.96 \\
\hline Immersion & 3.68 \\
\hline Knowledge Improvement & 4.40 \\
\hline Total Overall mean & $\mathbf{3 . 9 8}(\mathbf{7 9 . 6 \% )}$ \\
\hline
\end{tabular}

\section{Conclusion}

This paper describes how a mobile game, namely Basic Daily Life (BasLife), assists ASD children in developing their sensory skills. Even during the outbreak, this group of children should not be left behind. They should be given enough opportunities to develop essential skills.Sensory play can be intellectualized as a fun activity that involves children. Children should treat play skills using many inspection tools. This study showed that ASD 
children experienced an enjoyable moment and indirectly developed their senses while playing the game. Our findings highlight that $87.5 \%$ of ASD children between the ages of 6 and 12 prefer to play educational games instead of books. The availability of technology and digital devices can significantly enhance the learning process, even for ASD children during the COVID-19 pandemic.

\section{Acknowledgments}

We want to express our sincerest thanks to UiTM Cawangan Melaka for sponsoring this research under the Teja Internal Grant numbered GDT 2020-15. Their support is much appreciated. We also would like to express our gratitude to all individuals who were directly or indirectly involved in this study.

\section{References}

1. A. Yasuhara, "Correlation between EEG abnormalities and symptoms of autism spectrum disorder (ASD)," Brain Dev., vol. 32, no. 10, pp. 791-798, 2010.

2. N. Kapasia et al., "Impact of lockdown on learning status of undergraduate and postgraduate students during COVID-19 pandemic in West Bengal, India," Child. Youth Serv. Rev., vol. 116, p. 105194, 2020.

3. H. A. M. Noor, F. Shahbodin, and N. C. Pee, "Serious game for autism children: review of literature," World Acad. Sci. Eng. Technol., vol. 64, no. 124, pp. 647-652, 2012.

4. G.-J. Hwang, H.-Y. Sung, C.-M. Hung, I. Huang, and C.-C. Tsai, "Development of a personalized educational computer game based on students' learning styles,” Educ. Technol. Res. Dev., vol. 60, no. 4, pp. 623-638, 2012.

5. V.-M. Cojocariu and I. Boghian, "Teaching the Relevance of Game-based Learning to Preschool and Primary Teachers," Procedia - Soc. Behav. Sci., vol. 142, no. February 2015, pp. 640-646, 2014, doi: 10.1016/j.sbspro.2014.07.679.

6. L. C. Erickson, E. D. Thiessen, K. E. Godwin, J. P. Dickerson, and A. V Fisher, "Endogenously and exogenously driven selective sustained attention: Contributions to learning in kindergarten children," $J$. Exp. Child Psychol., vol. 138, pp. 126-134, 2015.

7. S. V. G. Cobb, "Virtual environments supporting learning and communication in special needs education," Top. Lang. Disord., vol. 27, no. 3, pp. 211-225, 2007.

8. S. Parsons and S. Cobb, "State-of-the-art of virtual reality technologies for children on the autism spectrum," Eur. J. Spec. Needs Educ., vol. 26, no. 3, pp. 355-366, 2011.

9. S. Parsons and P. Mitchell, "The potential of virtual reality in social skills training for people with autistic spectrum disorders," J. Intellect. Disabil. Res., vol. 46, no. 5, pp. 430-443, 2002.

10. S. Bernardini, K. Porayska-Pomsta, and T. J. Smith, "ECHOES: An intelligent serious game for fostering social communication in children with autism," Inf. Sci. (Ny)., vol. 264, pp. 41-60, 2014.

11. L. Malinverni, J. Mora-Guiard, V. Padillo, L. Valero, A. Hervás, and N. Pares, "An inclusive design approach for developing video games for children with Autism Spectrum Disorder," Comput. Human Behav., vol. 71, pp. 535-549, 2017.

12. L. Cadieux and M. Keenan, "Can Social Communication Skills for Children Diagnosed With Autism Spectrum Disorder Rehearsed Inside the Video Game Environment of Minecraft Generalize to the Real World?," JMIR Serious Games, vol. 8, no. 2, p. e14369, 2020.

13. E. Boutsika, "Kinect in education: A proposal for children with autism," Procedia Comput. Sci., vol. 27 , pp. 123-129, 2014.

14. V. Mc Manus, P. Corcoran, and I. J. Perry, "Participation in everyday activities and quality of life in preteenage children living with cerebral palsy in South West Ireland," BMC Pediatr., vol. 8, no. 1, p. 50, 2008.

15. M. Eversole et al., "Leisure activity enjoyment of children with autism spectrum disorders," J. Autism Dev. Disord., vol. 46, no. 1, pp. 10-20, 2016.

16. S. Y. Patterson, "A Novel Teacher Implemented Protocol to Assess Early Social Communication and Play Skills in Preschool Children with Autism." UCLA, 2013.

17. C. A. Miltenberger and M. H. Charlop, "Increasing the athletic group play of children with autism," $J$. Autism Dev. Disord., vol. 44, no. 1, pp. 41-54, 2014.

18. P. R. Benson, "Family influences on social and play outcomes among children with ASD during middle childhood," Res. Autism Spectr. Disord., vol. 7, no. 9, pp. 1129-1141, 2013.

19. L. L. Weaver, "Effectiveness of work, activities of daily living, education, and sleep interventions for people with autism spectrum disorder: A systematic review," Am. J. Occup. Ther., vol. 69, no. 5, pp. 6905180020p1-6905180020p11, 2015.

20. F.-L. Fu, R.-C. Su, and S.-C. Yu, "EGameFlow: A scale to measure learners' enjoyment of e-learning games," Comput. Educ., vol. 52, no. 1, pp. 101-112, Jan. 2009, doi: 10.1016/j.compedu.2008.07.004. 
21. A. M. Ern, "The use of gamification and serious games within interventions for children with autism spectrum disorder. A systematic review," no. September, pp. 1-37, 2014.

22. M. Davis, N. Otero, K. Dautenhahn, C. L. Nehaniv, and S. D. Powell, "Creating a software to promote understanding about narrative in children with autism: Reflecting on the design of feedback and opportunities to reason," 2007 IEEE 6th Int. Conf. Dev. Learn. ICDL, pp. 64-69, 2007, doi: 10.1109/DEVLRN.2007.4354045.

23. E. M. Whyte, J. M. Smyth, and K. S. Scherf, "Designing Serious Game Interventions for Individuals with Autism," J. Autism Dev. Disord., vol. 45, no. 12, pp. 3820-3831, 2015, doi: 10.1007/s10803-014-2333-1.

24. C. K. N. C. K. Mohd, F. Shahbodin, M. Sedek, and M. Samsudin, "Game based learning for autism in learning mathematics,” Int. J. Adv. Sci. Technol., vol. 29, no. 5, pp. 4684-4691, 2020. 